\title{
Transbronchial lung biopsy: a review of 85 cases
}

\author{
R. A. CLARK ${ }^{1}$, P. B. GRAY ${ }^{2}$, R. H. TOWNSHEND ${ }^{1}$, AND P. HOWARD ${ }^{1}$
}

From the Department of Respiratory Diseases, Lodge Moor Hospital ${ }^{1}$, Sheffield and the Department of Pathology, Northern General Hospital ${ }^{2}$, Sheffield, UK

Clark, R. A., Gray, P. B., Townshend, R. H., and Howard, P. (1977). Thorax, 32, 546-549. Transbronchial lung biopsy: a review of 85 cases. Transbronchial lung biopsy using the fibreoptic bronchoscope was carried out in 85 patients. There were no serious complications; two patients had a $10 \%$ pneumothorax and 17 had slight haemoptysis lasting less than 24 hours. The problems of interpreting small biopsy specimens are considered. Satisfactory specimens were obtained without fluoroscopic guidance, particularly in diffuse and lobar lesions. A histological diagnosis was made in $62 \%$ of diffuse lesions and compatible histology was found in a further $22 \%$. In a further case Pneumocystis carinii infection was diagnosed. Blind biopsy of discrete peripheral lesions was less successful with only one positive diagnosis in 12 patients.

Andersen et al. (1965) described a technique for transbronchial lung biopsy which involved the passage of rigid biopsy forceps through a Negus bronchoscope into a segmental bronchus. Although the results were good there was a high incidence of pneumothorax (Andersen and Fontana, 1972). The introduction of the fibreoptic bronchoscope and flexible forceps aroused further interest in the technique (Levin et al., 1974). Ellis (1975) has reported obtaining a histological diagnosis in between 60 and $80 \%$ of cases with no serious complications.

We have used a similar technique for 85 transbronchial lung biopsies without using fluoroscopic guidance and present here an analysis of our results.

\section{Patients and methods}

Eighty-five patients, 71 men and 14 women, aged 22 to 77 underwent fibreoptic bronchoscopy and transbronchial lung biopsy during investigation of their respiratory disease.

Patients fasted overnight were premedicated with $10 \mathrm{mg}$ of oral diazepam one hour, and $10 \mathrm{mg}$ of morphine and $0.6 \mathrm{mg}$ of atropine intramuscularly half an hour, before the procedure. The premedication was reduced if there was significant impairment of respiratory function.

The bronchoscopies were carried out under local anaesthesia using an Olympus BF 5 B2 fibreoptic bronchoscope. A Negus bronchoscope was passed and the fibrescope introduced through it in 77 patients while in the remaining eight the fibreoptic instrument was passed transnasally. The following $\stackrel{\vec{v}}{\nabla}$ technique was used for the biopsy. With the bronchoscope in the appropriate segmental bronchus the forceps, with a biopsy cup of $2 \mathrm{~mm} \times \sum$ $4 \mathrm{~mm}$, is passed into the bronchus and advanced until resistance is met. It is withdrawn 2 or $3 \mathrm{~cm}, \stackrel{2}{2}$ opened, and again advanced until resistance is $\stackrel{\mathbb{Q}}{\circ}$ met. The patient breathes out, and the forceps is $\overrightarrow{\vec{O}}$ closed and withdrawn with the biopsy specimen. 3 When the Negus bronchoscope is used the fibreoptic instrument with forceps in situ is withdrawn? between biopsies to avoid loss of tissue in the channel of the fibrescope. Fluoroscopy is not used. 음

In cases of diffuse lung disease biopsy specimens $\tilde{x}$ are taken where possible from each of the five lobes. In other cases at least two or three specimens are taken from the appropriate area.

After fixation in formol saline the tissue is prepared by the millipore filter technique and pro-음 cessed by conventional methods (see Grech et al., $\rightarrow$ 1977). Using this technique, $85 \%$ of the specimen is recovered and, even in the absence of solid N tissue, cells may be retained and cytological assess $-\infty$ ment made.

\section{Results}

In 80 patients at least one biopsy specimen showed lung tissue while in the remaining five bronchial $\stackrel{?}{+}$ mucosa was obtained. A total of $\mathbf{3 0 0}$ biopsies were $\frac{7}{T}$ performed of which 250 showed lung tissue.

DIFFUSE LUNG LESIONS

Of the 58 patients with diffuse changes on chesto 46 
radiography, 50 had features suggesting a clinical diagnosis, four had developed shadows while on immunosuppressive therapy, and in four there were no specific clinical features. Two hundred and twelve biopsies were performed, $94 \%$ showing lung tissue.

A clinical diagnosis based on the history, examination, and radiological and physiological findings was made in 50 patients (Table 1). In $31(62 \%)$ the histology of at least one biopsy confirmed the clinical diagnosis. In a further $11(22 \%)$, the features were non-specific but compatible with the diagnosis.

The patients classified as carcinomatosis had either diffuse nodular secondaries or lymphangitis carcinomatosa. Histological typing was possible in every case with a positive diagnosis (two cases of anaplastic, two small cell, two squamous cell, one adeno, and one poorly differentiated carcinoma).

In two patients the histology was at variance with the clinical diagnosis of cryptogenic fibrosing alveolitis. In the first, while the sections showed some features of alveolitis, there were clumps of atypical cells suggesting carcinoma. The subsequent clinical course has been that of cryptogenic fibrosing alveolitis. In the second patient the biopsy showed coal workers' pneumoconiosis.

A histological diagnosis of cryptogenic fibrosing alveolitis was made only in patients for whom this was the clinical diagnosis.

In six cases, tissue obtained by other techniques or at necropsy confirmed the biopsy histology.

A breakdown of the histological appearance of the 111 biopsy specimens from the 25 patients diagnosed as cryptogenic fibrosing alveolitis illustrates the variation in appearance between different areas of the lung. Thirty-six specimens showed characteristic features of the disease, in 29 there were non-specific fibrosis and distortion compatible with the diagnosis while normal lung tissue was obtained in 14 . Three specimens were incompatible with the diagnosis and suggested an alternative diagnosis. In the remaining 29 biopsies lung tissue was not obtained, bronchial mucosa being seen. All the biopsy specimens from the five patients who were on corticosteroids at the time showed non-specific changes.

In one of the four patients on immunosuppressive therapy the biopsy specimen showed Pneumocystis carinii, while in the others inflammatory changes were seen with no indication as to the aetiological agent. In no case were specimens sent for bacteriological examination.

A clinical diagnosis could not be made in four patients who were clinically well with normal respiratory function tests but with diffuse abnormalities on chest radiographs. Biopsies in these patients showed only minimal non-specific changes.

\section{LOCALISED LUNG LESIONS}

Twenty-seven patients studied had localised pulmonary disease; 12 had a single discrete peripheral opacity, six had lobar or segmental shadows, and nine had pleural lesions.

Blind biopsies were attempted in 12 patients with discrete peripheral lesions suggestive of bronchogenic carcinoma. Carcinoma was confirmed in one patient but in 11 non-specific changes only were seen. Tissue obtained by other means showed malignant change in eight while the clinical course has been that of carcinoma in all 12 .

In the six patients with lobar or segmental lesions a diagnosis of tuberculosis was made in two and of non-tubercular infection in three.

In the nine patients with pleural lesions several biopsy specimens were taken from different areas; in five the histology showed minimal non-specific changes, in three normal lung, and in one bronchial mucosa.

There were no complications from the bronchoscopy. Two patients had slight chest pain on biopsy and were found radiologically to have small pneumothoraces, neither requiring treatment.

Table 1 Analysis of transbronchial lung biopsy histology from 50 patients with diffuse reticulation or nodulation on chest $\mathrm{x}-$ ray

\begin{tabular}{|c|c|c|c|c|c|c|}
\hline \multirow[b]{2}{*}{ Clinical diagnosis } & \multirow[b]{2}{*}{ No. of cases } & \multicolumn{5}{|c|}{ Biopsy histology } \\
\hline & & $\begin{array}{l}\text { Confirmed } \\
\text { diagnosis }\end{array}$ & $\begin{array}{l}\text { Compatible but } \\
\text { non-specific }\end{array}$ & Incompatible & $\begin{array}{l}\text { Normal } \\
\text { lung }\end{array}$ & $\begin{array}{l}\text { Bronchial } \\
\text { mucosa }\end{array}$ \\
\hline Cryptogenic fibrosing alveolitis & 25 & 15 & 6 & 2 & 1 & 1 \\
\hline Sarcoidosis & 7 & 4 & 2 & 0 & 1 & 0 \\
\hline Carcinomatosis & 9 & 8 & 0 & 0 & 1 & 0 \\
\hline Pneumoconiosis & 8 & 4 & 2 & 0 & 0 & 2 \\
\hline Miliary tuberculosis & 1 & 0 & 1 & 0 & 0 & 0 \\
\hline Totals & 50 & 31 & 11 & 2 & 3 & 3 \\
\hline
\end{tabular}


Slight haemoptysis, which settled within 24 hours, followed the biopsy in 17 cases.

\section{Discussion}

There is a need for a simple, safe, repeatable method of obtaining lung tissue to establish a diagnosis or to follow the natural history of certain respiratory diseases. If the changes are patchy, diagnostic tissue may not be obtained from a single biopsy and the technique should permit biopsies from different areas during the same examination. Early reports (Levin et al., 1974; Ellis, 1975; Hanson et al., 1976) suggest that transbronchial lung biopsy using the fibreoptic bronchoscope and flexible forceps may go some way to fulfilling the above criteria. The fibreoptic bronchoscope allows a better view of the segmental bronchi, making it easier to choose the site of a biopsy. The bronchoscopy may be performed in ill patients in an intensive care unit and can be repeated with little distress. We would confirm the low incidence of complications (Credle et al., 1974; Ellis, 1975; Stableforth and Clark, 1976).

In other series (Ellis, 1975; Hanson et al., 1976) the biopsies have been performed under fluoroscopic guidance but these facilities were not routinely available for our bronchoscopy sessions. In diffuse or lobar lesions blind biopsies are acceptable as fluoroscopy adds little to the selection of the site for biopsy. Also, radiation may damage the fibre bundle (Ashby et al., 1976).

Routinely we pass the fibrescope through the Negus bronchoscope as this allows the instrument, with forceps in situ, to be removed between biopsies, thus preserving tissue and reducing the contamination of bacteriological specimens. Useful results have also been obtained using the transnasal approach in ill patients.

Small biopsy specimens present a problem to the pathologist in preparation and interpretation. The use of the millipore filtration technique has helped to retain tissue for processing (Grech et al., 1977).

The accuracy of a histological diagnosis depends on the size of the specimen. Lung lesions with specific pathological features, such as malignant cells, may be recognised from small biopsy specimens, as demonstrated by the high success rate in the diffuse carcinomatosis group. Cryptogenic fibrosing alveolitis in the desquamative phase may be easily recognised but in the advanced stage with extensive fibrosis and few specific features a definitive diagnosis may be difficult to make.

In an industrial community carbon pigment and a degree of non-specific fibrosis are common in the lung around the terminal bronchioles. As it is from this area that the transbronchial lung biopsies $\overrightarrow{\overline{\vec{D}}}$ are taken, these changes add to the difficulties ofo interpretation, particularly where pneumoconiosis is suspected.

In spite of these problems in $62 \%$ of diffuse $\frac{{ }_{\alpha}}{\alpha}$ lesions the biopsies established, and in a furthero $22 \%$ were consistent with, the clinical diagnosis. $\rightarrow$ When dealing with small biopsy specimens it is important to consider the histology in the context $\vec{\omega}$ of the clinical, radiological, physiological, ando biochemical information. Used in this way the $\vec{x}$ results have been of considerable value.

The patchy nature of many diffuse lesions re- $\stackrel{N}{G}$ quires four or five specimens to be taken fromis different areas to increase the likelihood of suc-卢 cess. The finding of non-specific fibrotic changes in윽 five patients with cryptogenic fibrosing alveolitiestaking corticosteroids at the time of biopsy sug-O gests that, where possible, biopsies should be per- $-\stackrel{+}{0}$ formed before the start of treatment.

Our experience in patients on immunosuppressive therapy is limited. In one case the diagnosis of Pneumocystis carinii pneumonia was established. $V$ Where this disease is suspected a transbronchialo lung biopsy should be considered (Scheinhorn ets al., 1974; Andersen, 1974). Unusual organisms, in-⿳亠二口犬 cluding fungi, may invade the lungs of such patients and, while showing inflammatory changes, $\stackrel{\AA}{\varrho}$ the organisms may not be detected histologically. $\overrightarrow{\vec{A}}$ Tissue sent for bacteriological examination may3 help to isolate the aetiological agent. Patients on cytotoxic drugs may have low platelet counts ando require a platelet transfusion to cover the biopsy and prevent bleeding.

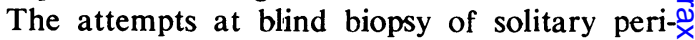
pheral lesions were disappointing. We have usedo several techniques for obtaining material for histo logical examination in such cases and the resultsô are shown in Table 2 . The blind biopsy was the 3 least successful, and even transbronchial biopsy윽 under fluoroscopic guidance was less rewarding than percutaneous aspiration needle biopsieso (Grech et al., 1977; Grech, 1976). In our experi-n ence, blind biopsy of peripheral coin lesions has. little place. Other workers have had greater suc- $N$

Table 2 A comparison of techniques for biopsy of discrete peripheral lesions

\begin{tabular}{|c|c|c|c|}
\hline Biopsy technique & No. of cases & $\begin{array}{l}\text { No. of cases } \\
\text { with positive } \\
\text { histology }\end{array}$ & $\begin{array}{l}\% \\
\text { Success } \\
\text { rate }\end{array}$ \\
\hline $\begin{array}{l}\text { Blind transbronchial biopsy } \\
\text { Transbronchial biopsy }\end{array}$ & 12 & 1 & 8 \\
\hline $\begin{array}{l}\text { under fluoroscopy } \\
\text { Aspiration needle biopsy }\end{array}$ & $\begin{array}{l}14 \\
50\end{array}$ & $\begin{array}{r}5 \\
46\end{array}$ & \begin{tabular}{ll}
$38 \cdot 5$ \\
92 & \multicolumn{2}{c}{}
\end{tabular} \\
\hline
\end{tabular}


cess in taking biopsy specimens from these lesions using fluoroscopic guidance (Hanson et al. (1976) $71 \%$ and Ellis (1975) up to $81 \%$ success, depending on the size of the lesion).

In contrast, transbronchial lung biopsy in patients with segmental or lobar lesions may aid diagnosis while in selected cases of pleural lesions the finding of minimal non-specific abnormalities in several specimens has helped in clinical assessment.

The technique of transbronchial lung biopsy by the fibreoptic bronchoscope has proved safe and easy to perform and has permitted the removal of tissue from several areas. We feel its great value lies in the diagnosis of diffuse lung disease.

\section{References}

Andersen, H. A. (1974). A safe procedure for diagnosis of Pneumocystis carinii pneumonia. Chest, 66, 222223.

Andersen, H. A., and Fontana, R. S. (1972). Transbronchoscopic lung biopsy for diffuse pulmonary diseases; technique and results in 450 cases. Chest, 62, 125-128.

Andersen, H. A., Fontana, R. S., and Harrison, E. G., Jr. (1965). Transbronchoscopic lung biopsy in diffuse pulmonary disease. Diseases of the Chest, 48, 187192.

Ashby, B. S., Goodman, D. A., and Marlton, A. P. (1976). The effects of radiation on the fibre-optic duodenoscope. Abstracts of the European Congress on Gastrointestinal Endoscopy, Budapest, 208.
Credle, W. F., Jr., Smiddy, J. F., and Elliott, R. C. (1974). Complications of fibreoptic bronchoscopy. American Review of Respiratory Diseases, 109, 67-72.

Ellis, J. H., Jr. (1975). Transbronchial lung biopsy via the fibreoptic bronchoscope. Chest, 68, 524-532.

Grech, P. (1976). Aspiration lung biopsy (abstract). British Journal of Diseases of the Chest, 70, 284.

Grech, P., Gray, P. B., Lambourne, C. A., Clark, R. A., and Townshend, R. H. (1977). Aspiration needle biopsy for solitary, peripheral lung lesions. British Journal of Diseases of the Chest (In press).

Hanson, R. R., Zavala, D. C., Rhodes, M. L., Keim, L. W., and Smith, J. D. (1976). Transbronchial biopsy via flexible fiberoptic bronchoscope: results in 164 patients. American Review of Respiratory Diseases, 114, 67-72.

Levin, D. C., Wicks, A. B., and Ellis, J. H., Jr. (1974). Transbronchial lung biopsy via the fibreoptic bronchoscope. American Review of Respiratory Diseases, 110, 4-12.

Scheinhorn, D. J., Joyner, L. R., and Whitcomb, M. E. (1974). Transbronchial forceps lung biopsy through the fibreoptic bronchoscope in Pneumocystis carinii pneumonia. Chest, 66, 294-295.

Stableforth, D. B., and Clarke, S. W. (1976). Flexible fibre-optic bronchoscopy. British Journal of Clinical Equipment (July Supplement to British Journal of Hospital Medicine), 1, 172-182.

Requests for reprints to: Dr. R. A. Clark, Department of Respiratory Diseases, Lodge Moor Hospital, Sheffield S10 4LH, UK. 